\title{
CERTAIN SUBCLASS OF MEROMORPHICALLY UNIFORMLY CONVEX FUNCTIONS WITH POSITIVE COEFFICIENTS
}

\author{
BOLINENI VENKATESWARLU, PINNINTI THIRUPATHI REDDY, and NEKKANTI \\ RANI
}

\begin{abstract}
In this paper we introduce and study a new subclass of meromorphically uniformly convex functions with positive coefficients defined by a differential operator and obtain coefficient estimates, growth and distortion theorems, radius of convexity, integral transforms, convex linear combinations, convolution properties and $\delta$-neighborhoods for the class $\sigma_{p}(\alpha, \beta, \lambda)$.
\end{abstract}

MSC 2010. 30C45.

Key words. Coefficient estimates, uniformly convex, uniformly starlike.

\section{REFERENCES}

[1] O.P. Ahuja, G. Murugusundaramurthy and N. Magesh, Integral means for uniformly convex and starlike functions associated with generalized hypergeometric functions, Journal of Inequalities in Pure and Applied Mathematics, 8 (2008), 118 -127.

[2] R. Bharathi, R. Parvatham and A. Swaminathan, On subclasses of uniformly convex functions and corresponding class of starlike functions, Tamkang J. Math., 28 (1997), $17-32$.

[3] J. Clunie, On meromorphic schlicht functions, J. Lond. Math. Soc., 34 (1959), 215-216.

[4] A.W. Goodman, Univalent functions and non-analytic curves, Proc. Amer. Math. Soc., 8 (1957), 598-601.

[5] A.W. Goodman, On uniformly convex functions, Ann. Polon. Math., 56 (1991), 87-92.

[6] A.W. Goodman, On Uniformly starlike functions, J. Math. Anal. Appl., 155 (1991), 364-370 .

[7] O.P. Juneja and T.R. Reddy, Meromorphic starlike univalent functions with positive coefficients, Ann. Univ. Mariae Curie-Skłodowska Sect. A, 39 (1985), 65-76.

[8] S. Kanas and A. Wisniowska, Conic regions and k-uniform convexity, Comput. Appl. Math., 105 (1999), 327-336.

[9] S. Kanas and A. Wisniowska, Conic domains and starlike functions, Rev. Roumaine Math. Pures Appl., 45 (2000), 647-657.

[10] B. Madhavi, T. Srinivas and P. Thirupathi Reddy, A new subclass of meromorphically uniformly convex functions with positive coefficients, Palest. J. Math., 6 (2017), 179-187.

[11] M.L. Mogra, T.R. Reddy and O.P. Juneja, Meromorphic univalent functions with positive coefficients, Bull. Aust. Math. Soc., 32 (1985), 161-176.

The authors would like to express sincere thanks to the esteemed referee(s) for their careful reading, valuable suggestions and comments, which helped them to improve the presentation of this paper.

DOI: 10.24193/mathcluj.2019.1.08 
[12] G. Murugusundarmurthy and N. Magesh, Certain subclasses of starlike functions of complex order involving generalised hypergeometric functions, Int. J. Math. Math. Sci., 2010, Article 178605, 1-12.

[13] Ch. Pommerenke, On meromorphic starlike functions, Pacific J. Math.,13 (1963), 221235.

[14] F. Ronning, On starlike functions associated with parabolic regions, Ann. Univ. Mariae Curie-Skłodowska Sect. A, 45 (1991), 117-122.

[15] F. Ronning, Uniformly convex functions and a corresponing class of starlike functions, Proc. Amer. Math. Soc., 118 (1993), 189-196.

[16] W.C. Royster, Meromorphic starlike multivalent functions, Trans. Amer. Math. Soc., 107 (1963), 300-308.

[17] St. Ruscheweyh, Neighbourhoods of univalent functions, Proc. Amer. Math. Soc., 81 (1981), 521-527.

[18] H. Silverman, Univalent functions with negative coefficients, Proc. Amer. Math. Soc., 51 (1975), 109-116.

[19] P.T. Reddy, B. Venkateswarlu and N. Rani, On a new subclass of involving meromophically convex functions with positive coefficients, submitted.

[20] B.A. Uralegaddi and M.D. Ganigi, A certain class of meromorphically starlike functions with positive coefficients, Pure Appl. Math. Sci., 26 (1987), 75-81.

[21] B. Venkateshwarlu, P.T. Reddy and N. Rani, Certain subclass of meromorphic functions involving generalized differential operator, submitted.

Received March 11, 2018

Accepted October 30, 2018
GST, GITAM University

Department of Mathematics

Doddaballapur - 561203

Bengaluru Rural, India

E-mail: bvlmaths@gmail.com

Kakatiya University

Department of Mathematics

Warangal - 506009

Telangana, India

E-mail: reddypt2@gmail.com

Praveenya Institute of Marine Engineering and Maritime Studies

Department of Sciences and Humanities Modavalasa - 534002

Visakhapatnam, A. P. , India

E-mail: raninekkanti1111@gmail.com 